\title{
Evolution of advertisement calls in African clawed frogs
}

\author{
Martha L. Tobias ${ }^{1,4}$, Ben J. Evans ${ }^{2,3}$, and Darcy B. Kelley ${ }^{1,2}$ \\ ${ }^{1}$ Department of Biological Sciences, Columbia University, New York, NY, USA \\ ${ }^{2}$ Department of Ecology, Evolutionary and Environmental Biology, Columbia University, New \\ York, NY, USA \\ ${ }^{3}$ Department of Biology, McMaster University, Hamilton, ON, Canada
}

\section{Summary}

For most frogs, advertisement calls are essential for reproductive success, conveying information on species identity, male quality, sexual state and location. While the evolutionary divergence of call characters has been examined in a number of species, the relative impacts of genetic drift or natural and sexual selection remain unclear. Insights into the evolutionary trajectory of vocal signals can be gained by examining how advertisement calls vary in a phylogenetic context. Evolution by genetic drift would be supported if more closely related species express more similar songs. Conversely, a poor correlation between evolutionary history and song expression would suggest evolution shaped by natural or sexual selection. Here, we measure seven song characters in 20 described and two undescribed species of African clawed frogs (genera Xenopus and Silurana) and four populations of X. laevis. We identify three call types — click, burst and trill that can be distinguished by click number, call rate and intensity modulation. A fourth type is biphasic, consisting of two of the above. Call types vary in complexity from the simplest, a click, to the most complex, a biphasic call. Maximum parsimony analysis of variation in call type suggests that the ancestral type was of intermediate complexity. Each call type evolved independently more than once and call type is typically not shared by closely related species. These results indicate that call type is homoplasious and has low phylogenetic signal. We conclude that the evolution of call type is not due to genetic drift, but is under selective pressure.

\section{Keywords}

call types; phylogenetic signal; vocal behaviour; Xenopus; Silurana

\section{Introduction}

Comparative phylogenetic analysis of variation among species provides a powerful tool for unravelling the evolution of a phenotype. This approach can be especially informative for the evolution of reproductive behaviours, as these are often labile and subject to natural and sexual selection. For example, a weak or absent correlation between evolutionary history and behaviour (i.e., low phylogenetic signal) suggests that selection is operating while a strong correlation (i.e., high phylogenetic signal) is consistent with evolution by genetic drift (Cocroft \& Ryan, 1995; Ryan, 1995; Cannatella et al., 1998; Revell et al., 2008). A high phylogenetic signal can also be achieved if a trait initially diverged but was conserved thereafter (Kusmierski et al., 1993). Comparisons between phylogenetic history and behaviour also provide information about whether a phenotype has been evolving towards

(c) Koninklijke Brill NV, Leiden, 2011

${ }^{4}$ Corresponding author's mt18@ columbia.edu. 
increased complexity (Weber \& Hoekstra, 2009; Lovejoy et al., 2010), whether behavioural modifications occurred with speciation (Martins et al., 2004), whether traits covary (Ord et al., 2001; Price et al., 2007; Thierry et al., 2008) and, in the case of sexual selection, whether the primary driving force was female choice or male competition (Borgia \& Coleman, 2000; Morris et al., 2007).

Acoustic signalling is employed by many species to convey information on species identity, mate fitness, sexual state, and location (Bradbury \& Vehrencamp, 1998). The central role of vocalizations in courtship makes them prime targets for sexual selection. Male vocal signals attract females, and female preference for specific features drives divergence of signals in many species (Gentner \& Hulse, 2000; Pfennig et al., 2000; Kime et al., 2004; Castellano \& Rosso, 2006; Castellano et al., 2009b; Gerhardt \& Brooks, 2009). Vocal behaviours also function in male-male competition and are, thus, subject to intra-sexual selection (Sanvito et al., 2007; Dubois et al., 2009; Tobias et al., 2010). Vocal signals are subject to natural selection when habitat affects signal transmission (Ryan \& Brenowitz, 1985) or leads to heightened risk of predation (Ryan et al., 1982).

We have identified cellular and molecular processes that contribute to the expression of male advertisement calls in two species from two genera of African clawed frogs, Xenopus laevis and Silurana tropicalis (Kelley \& Tobias, 1999; Nasipak \& Kelley, 2008). The availability of a robust molecularly-based phylogeny for the African clawed frogs — family Pipidae, subfamily Xenopodinae - (reviewed in Evans, 2008) now allows us to study the evolution of advertisement calls in the context of their evolutionary history. In the long run, the combination of phylogenetic, physiological and genomic approaches should yield additional insight into the evolutionary neuroethology of vocal signalling.

African clawed frogs are aquatic throughout their life cycle (including adulthood) and rely heavily on acoustic signals for successful mating. In X. laevis South Africa, the most intensively studied species, advertisement calls play a key role in both male-male competition and in female attraction. Vocally dominant males suppress advertising in near neighbours and females swim towards an advertising conspecific male (Picker, 1983; Tobias et al., 2004). Both approach and vocal suppression can be elicited by broadcasting advertisement calls from a speaker, indicating that acoustic signals alone are sufficient for communication, without the confounding effects of visual or olfactory co-signals (Tobias et al., 2010).

Phylogenetic relationships among species of African clawed frog have been estimated using mitochondrial and nuclear DNA (Evans, 2008). African clawed frogs are divided into two genera: Silurana (two described and two undescribed species), and Xenopus (19 described and three undescribed species). Silurana includes one diploid and three tetraploid species and Xenopus includes 12 tetraploid, seven octaploid and three dodecaploid species. In both genera, the generation of extant tetraploids is thought to have occurred only once. In Xenopus, octaploids and dodecaploids originated independently at least six times. Where known, polyploidization occurred by interspecies hybridization resulting in whole genome duplication (allopolyploidization; Evans, 2007, 2008). The phylogenetic history of African clawed frogs, thus, includes evolutionary lineages that bifurcate and those that reticulate through time.

Vocalizations of African clawed frogs comprise numerous temporal and spectral features. Here we measure seven call characters in male advertisement calls from 22 species and four populations of African clawed frogs. These data allow us to categorize advertisement calls into four call types and examine variation of advertisement call types in a phylogenetic context. These comparisons are then used to predict the ancestral call type, to examine the 
evolution of call complexity and to evaluate the relationship between phylogenetic history and call type.

\section{Methods}

\subsection{Animals}

We recorded advertisement calls from 20 described species, two undescribed species ( $S$. new tetraploid 1 and $X$. new tetraploid) and four geographically distinct populations of $X$. laevis. Six species/populations of X. laevis (sensu Kobel et al., 1996) are included; these have been variably referred to as 'sub-species' because hybridizations between populations produce fertile offspring (Blackler \& Fischberg, 1965; Kobel et al., 1996) or considered as full species (Measey \& Channing, 2003). In this study, we follow the taxonomy of Amphibiaweb (http://amphibiaweb.org/) and the Amphibian Species of the World database (http://research.amnh.org/vz/herpetology/amphibia/index.php) for X. laevis, X. victorianus and $X$. petersi. Within $X$. laevis, we refer to four populations with distinct vocalizations by their respective collection localities (X. laevis South Africa, X. laevis Congo, X. laevis Malawi and X. laevis Nigeria); for brevity, the word 'from' is not included before the location name and 'Congo' refers to the Republic of Congo (Brazzaville). Whether these populations merit full species status remains unclear, but is supported by the finding that each population has a unique advertisement call (reported here). Only one described, extant species, $X$. longipes, and two putative undescribed species $X$. cf. fraseri 1 and $X$. cf. boumbaensis (known only from museum specimens) are not included as we were unable to obtain live males.

Some species were provided by commercial suppliers (S. tropicalis, Xenopus 1, S. epitropicalis, Pacific Biology, X. laevis South Africa, Xenopus 1, X. borealis, Xenopus Express); others were part of a collection at the University of Geneva (X. fraseri, $X$. pygmaeus, $X$. ruwenzoriensis, $X$. amieti, X. boumbaensis, X. andrei, X. wittei, X. largeni, $X$. laevis Malawi, X. laevis Congo, $X$. victorianus, $X$. laevis Nigeria, $X$. petersi, X. muelleri, $X$. new tetraploid, $X$. clivii) or the University of Bristol (X. vestitus). Some were collected by the authors: $S$. new tetraploid 1 by MLT and DBK, X. itombwensis and X. lenduensis by BJE and $X$. gilli by MLT. Animals used for recording and genetic material for the molecular phylogeny came from the same location and source (Evans et al., 2004).

\subsection{Recordings}

To promote vocal behaviour, males were injected with human chorionic gonadotropin (hCG; Sigma: 50-200 IU depending on body size) one day prior to and on the day of recording (Wetzel \& Kelley, 1983). Males were paired with a conspecific, sexually unreceptive female in a glass aquarium $\left(60 \times 15 \times 30.5 \mathrm{~cm}, \mathrm{~L} \times \mathrm{W} \times \mathrm{H}\right.$; water depth $\left.=23 \mathrm{~cm} ; 20^{\circ} \mathrm{C}\right)$. A hydrophone (High Tech, Gulfport, MI, USA; output sensitivity $-164.5 \mathrm{~dB}$ at $1 \mathrm{~V} / \mu \mathrm{Pa}$, frequency sensitivity $0.015-10 \mathrm{kHz}$; or Cornell Bioacoustics, output sensitivity $-163 \mathrm{~dB}$ at 1 $\mathrm{V} / \mu \mathrm{Pa}$ ) was used to record calls to a Marantz digital recorder (CDR300, Marantz, Mahwah, NJ, USA; $44.1 \mathrm{kHz}$ sampling rate). Recordings were subsequently analyzed using Signal software (Engineering Design, Berkeley, CA, USA) running on a Dell (Microsoft Windows $\mathrm{XP}$ ). Calls are represented here as waveforms (sound intensity as a function of time) and spectrograms (frequency as a function of time).

The advertisement call is produced in the presence of both males and females and is the predominant male call (Gerhardt \& Huber, 2002). To distinguish advertisement calls from other call types, whenever possible we recorded each male vocalizing in three contexts: in isolation, paired with another conspecific male, and paired with a conspecific female. The call produced in all three situations was identified as the advertisement call. Between one 
and three individual males were recorded for each species depending on availability; the data for each individual are shown in Tables 1 and 2.

In African clawed frogs, vocalizations are composed of clicks, a brief sound produced when arytenoid cartilages in the larynx pull apart (Yager, 1992b; Figure 1A). Clicks are functionally equivalent to the sound pulses produced by terrestrial frogs. For each species, we defined an advertisement call as the smallest vocal unit (SVU) containing a characteristic and repeating pattern of clicks and spectral peaks (Figure 1B). Males rarely produce a single SVU but instead call in bouts; a bout is a sequence of SVUs in which the interval between SVUs is roughly constant (Figure 1C). A bout was defined as ending when the interval between SVUs exceeded the mean + SD of the inter-SVU interval. Thus, while an SVU contains a characteristic number of clicks, bouts are composed of a variable number of SVUs.

All SVUs contain one or two dominant frequencies. A fast Fourier transform analysis was performed for each SVU and the two frequencies with the greatest sound intensities (dominant frequencies, DF) were identified. DF1 and DF2 represent the lower and higher dominant frequencies respectively.

For each species, we measured the number of clicks/SVU $(\mathrm{CN})$, the inter-click interval (ICI; time from the onset of one click to the onset of the following click), DF1 and DF2 (if present), intensity modulation (IM; the fold change in amplitude from the first click to the highest intensity click in an SVU ( $\max -\min ) / \mathrm{min})$, the inter-SVU interval (iSVUi; time from the onset of one SVU to the onset of the following SVU), and call duty cycle (CDC; the total time spent calling/total bout length). For CN, DF1, DF2 and IM, there is one measurement/SVU. ICI is the mean for all intervals within one SVU. CDC and iSVUi are both measured from bouts. Since bouts generally include more SVUs than were used for the measurement/SVU, SVUs for the two data sets are overlapping but not identical. Amplitude depends on the position of the animal relative to the hydrophone as well as on how loudly the frog calls. Thus, amplitude cannot be compared across calls and there are no units shown for amplitude in the figures. The numbers of animals, SVUs and clicks examined for each species are indicated in Tables 1 and 2 . Since the number of clicks/SVU varies dramatically between species (from 1 to 127), the number of SVUs we examined varied.

Measurements for central tendency are expressed as mean \pm SD throughout the text. For comparisons of call characters across call type groups, the mean of means for each species is used and the DF is the number of species. Call characters were compared across call type using Student's $t$-test (when comparing across two call types) or an ANOVA (when comparing across three call types); a Tukey multiple comparison post-hoc test was performed when the ANOVA was significant at $a=0.05$. A Pearson correlation coefficient was used to compare body size (snout-vent length, SVL) to dominant frequency. To determine whether call characters differ with ploidy in Xenopus, a Student's $t$-test was used to compare call character species means between tetra- and octoploid species. An ANOVA was used to compare each call character between the Silurana species; in this comparison, all values (rather than means) were used.

\subsection{Phylogenetic analyses}

The reticulated phylogeny of African clawed frogs prevents the use of model-based approaches that assume a bifurcating evolutionary history (e.g., Felsenstein, 1985; Blomberg et al., 2003; Pagel et al., 2004). Instead, here we use maximum parsimony as an optimality criterion to examine the variation of advertisement call types within the context of a reticulate phylogeny. If two descendant lineages have different types of calls, we assume that their most recent common ancestor (MRCA) could have had either type. If one 
descendant lineage had two possible call types and the other had only one, we assume their MRCA had the call type (or set of call types) that was shared by both descendant lineages.

\section{Results}

\subsection{Advertisement call types in African clawed frogs}

A representative SVU for each species is shown on a phylogenetic tree estimated from molecular data (Evans, 2008; Figure 2). Although the advertisement calls of some closely related species, such as $X$. borealis and $X$. new tetraploid, are quite similar, each species' advertisement call can be distinguished by at least one temporal and/or spectral parameter (Table 1). The temporal structure of calls varies from simple single clicks (e.g., X. borealis) to complex calls with two temporal patterns (e.g., X. laevis South Africa). This observation led us to classify advertisement calls according to temporal properties.

The group with the smallest number of clicks has an SVU composed of only one click and is referred to as 'click type' (Table 1; example in Figure 3A, the sound file can be accessed via http://www.media.brill.nl/beh/148/4, Supplementary material 1); three species produce this call type. For click type calls, there is virtually no variability in click number (one $X$. boumbaensis male produced only two doublets in 154 calls). Because the SVU comprises only one click, neither intensity modulation nor inter-click interval can be measured, and this call type, thus, constitutes a unique category. The second call type contains relatively few clicks, from 2 to 14, and is referred to as 'burst type' (Table 1, Figure 3B, the sound file can be accessed via http://www.media.brill.nl/beh/148/4, Supplementary material 2). There are 10 species and one population of $X$. laevis that produce burst type calls. A third call type contains a large number of clicks, from 43 to 127 and is referred to as 'trill type' (Table 1, Figure 3C, the sound file can be accessed via http://www.media.brill.nl/beh/148/4, Supplementary material 3). There are six species that produce trill type calls. Burst and trill type calls are readily discriminated by the large gap in click number between them, so this categorization is based on a natural distinction. The number of clicks/SVU is discontinuous across call types ((mean $\pm \mathrm{SD}$, range) $1.0 \pm 0.0,1.0$ for click; $5.86 \pm 3.81,2-14.8$ for burst and $74.3 \pm 33.9,43.4-127.0$ for trill-type calls).

To determine if any call character, other than click number, differs by call type, we first compared call characters that are present in all three call types. Inter-SVU interval varies significantly with call type (ANOVA, $p=0.02, F=4.98, \mathrm{DF}=2$, 17). Burst type calls have significantly shorter iSVUis than trill type calls $(p<0.05)$. While click type calls have even shorter iSVUis (click $=580.3 \pm 386$, burst $=699.4 \pm 936.8$, trill $=2378 \pm 1536$ ), they are not significantly different from burst or trill type calls. There is no difference in CDC between call types (click $=0.199 \pm 0.141$, burst $=420.42 \pm 0.26$, trill $=0.448 \pm 0.16 ; p=0.27, F=$ $1.42, \mathrm{DF}=2,17)$. $\mathrm{CDC}$ is the relative proportion of call time to silence in a bout of calling and is, thus, an indicator of call energy. That click number and iSVUi differ between burst and trill types but CDC does not, suggests that in general a small click number is compensated for by a shorter interval so that the energy expenditure within a bout of calling is similar in the two call types. There are however exceptions, the most extreme being $X$. ruwenzoriensis, which has a small click number (3.4) and a very long iSVUi (3244 ms).

Advertisement calls of Silurana species can be distinguished from those of Xenopus species by dominant frequency (Figure 4). All Silurana species have a single low frequency dominant peak $(<750 \mathrm{~Hz})$ while all Xenopus species have two, higher frequency dominant peaks ( $>1 \mathrm{kHz}$; Tables 1 and 2). Among Xenopus species, there is no difference across call types in DF1 (click $=1772 \pm 616$, burst $=1885 \pm 221$, trill $=1649 \pm 366 ; p=0.46, F=0.82$, $\mathrm{DF}=2,15)$ or DF2 (click $=2768 \pm 437$, burst $=2424 \pm 245$, trill $=2122 \pm 466 ; p=0.06, F$ $=3.34)$. 
Intensity modulation and inter-click interval can be compared only between burst and trill type calls. Burst type calls have significantly less intensity modulation than trill type ( $t$-test, burst $=6.49 \pm 1.96$, trill $=39.22 \pm 15.58 ; p=0.012, t=2.85, \mathrm{DF}=15)$ perhaps because there are fewer clicks over which intensity increases (click volume typically gets progressively louder throughout the SVU; see Figures 1-4). There is no significant difference in ICI between burst and trill type calls (burst $=18.86 \pm 3.45$, trill $=20.04 \pm 5.33$; $p=0.85, t=0.19, \mathrm{DF}=15)$.

Biphasic calls are composed of two, rather than one, temporal patterns (see example in Figure 5B, Table 2, the sound file can be accessed via http://www.media.brill.nl/beh/148/4, Supplementary material 4); four species produce biphasic calls. However, some call characters that distinguish single phase call types cannot be measured in biphasic calls. For example, iSVUi is shorter in burst than in trill type calls but bursts or trills are not repeated in tandem in biphasic calls; instead, the iSVUi is the interval between the start of one biphasic call and the start of the next. Thus, the two phases of a biphasic call are distinguished by click number only, and the terminology used to describe them reflects that used for single phase callers, i.e., click type calls contain one click.

Xenopus laevis South Africa (Figure 5B) and X. laevis Malawi (Figure 6A) both produce a burst followed by a trill with no pause between phases (Table 2); thus, calling is continuous within a bout (Figure 6B). Xenopus laevis Congo (Figure 6A) produces a burst followed by a single click; the interval between the end of the burst and the beginning of the click is longer $(84.67 \pm 4.88 \mathrm{~ms})$ than the interval between clicks but shorter than the interval between SVUs (Table 2). Xenopus itombwensis produces a trill followed by a slow burst with no intensity modulation (Figure 6A, Table 2). In X. laevis South Africa both phases are produced in every SVU while in X. laevis Malawi, X. laevis Congo and X. itombwensis, males sometimes produce only the first phase; the biphasic call, however, is most common.

Silurana epitropicalis produces calls that do not fit into any of the categories described above (Figure 6C, Table 2). Calls include bursts alone, trills alone or (most frequently) a trill followed by a bout of bursts. Although the calls include two phases, they differ from other biphasic calls in that the order of the phases is random rather than alternating (Figure 6D). The result is an irregular call pattern during bouts of calling (compare bouts from X. laevis Malawi and S. epitropicalis, Figure 6B and D).

In summary, advertisement calls of African clawed frogs can be grossly divided into two call categories: those with a single temporal pattern and those with two temporal patterns. The number of clicks per SVU was used to further classify the single temporal pattern advertisement calls into three types: click, burst and trill. Burst and trill call types differ significantly in the interval between SVUs and intensity modulation. Call duty cycle, interclick interval and frequency do not differ between call types. Multiple call types are represented in both genera but Silurana calls differ significantly in frequency from Xenopus calls. Calls vary in complexity from a simple, single click call to a complex, biphasic call.

\subsection{Call characters and ploidy}

Genome duplication could have an impact on vocal characteristics if, for example, aspects of the phenotype are dosage-dependent or influenced by cell or nucleus size, as postulated in Hyla (Ptacek et al., 1994; Keller \& Gerhardt, 2001). Pulse rate and ploidy are negatively correlated in Hyla and Bufo (Castellano et al., 2002). We explored the relation between ploidy and call characters in the genus Xenopus, which includes a large number of polyploid species. We compared tetraploid (11) with octaploid (6) species because this doubling of ploidy is analogous to the above study (the one dodecaploid species was excluded). Analyses were confined to single phase callers so that all call characters could be 
considered. No call character was significantly correlated with ploidy $(t$-test, $\mathrm{DF}=15$; iSVUi: $t=2.02, p=0.06$; CN: $t=0.80, p=0.43$; CDC: $t=0.15, p=0.88$; DF1: $t=0.73, p=$ 0.48 ; DF2: $t=0.76, p=0.46$; IM: $t=0.12, p=0.91$; ICI: $t=0.57, p=0.58$ ).

Within one species pair of hylids, $H$. chrysoscelis and $H$. versicolor, in which the higherploidy species is a descendant of the lower ploidy species (Holloway et al., 2006) pulse rate doubles with halving ploidy level. A similar phylogenetic relationship is found between the diploid S. tropicalis and the tetraploids $S$. epitropicalis and $S$. new tetraploid 1. Call characters were, thus, compared among the three Silurana species (S. tropicalis, S. new tetraploid 1 and both phases of S. epitropicalis where applicable). Although CDC differs significantly between the three species $(p=0.047, F=3.43, \mathrm{DF}=2,27)$, post hoc tests reveal that $S$. tropicalis is significantly different from S. epitropicalis $(0.481 \pm 0.287$ vs. $0.684 \pm 0.148)$ but not from S. new tetraploid $1(0.537 \pm 0.093)$. Similarly, there is a significant overall difference in ICI $(p<0.0001, F=223.7, \mathrm{DF}=3,87)$, but this difference is not related to ploidy because the two tetraploids are also significantly different from each other (S. tropicalis $=36.4 \pm 2, S$. new tetraploid $1=14.5 \pm 2.2$, S. epitropicalis: burst phase $=23.03$, trill phase $=22.2 \pm 2.2$ ). Only iSVUi is negatively correlated with ploidy $(S$. tropicalis $=1124 \pm 925.7, S$. new tetraploid $1=287.7 \pm 44.4$, S. epitropicalis burst $=422.5$ $\pm 106.8 ; p<0.0001, F=50.5, \mathrm{DF}=2,172$ ). Species differences in iSVUi may reflect differences in call type rather than ploidy, since iSVUi is shorter in burst (higher ploidy) than trill (lower ploidy) type calls.

\subsection{Body size and call type}

Body size is inversely correlated with dominant frequency in some bird and anuran species (Wallschlager, 1980; Ryan, 1988). To test whether this is the case in African clawed frogs, we reviewed data on snout vent length (SVL) for the single phase callers (Table 1; including data from Kobel et al., 1996; Evans et al., 2008, 2011) and calculated the correlation coefficient between body length and both dominant frequencies. We found no significant correlation between SVL and DF1 $(r=0.033, p=0.9, N=20)$ or DF2 $(r=0.19, p=0.45, N$ $=18$; Pearson correlation). For example, both dominant frequencies are lower in the smaller species $X$. vestitus than in larger species such as X. muelleri, or X. laevis South Africa (Table $1)$.

\subsection{Evolution of call types}

We evaluated the evolution of call types in the context of a reticulating phylogenetic history using the maximum parsimony optimality criterion. Burst and trill types are most common (11 and 6 species/populations, respectively) and click and biphasic call types are least common ( 3 and 5 species/populations, respectively). The most parsimonious scenario for call type phylogeny is that the ancestral call type was a burst (Figure 7). Click, trill and biphasic call types all evolved more than once and on distantly related branches. These observations do not support a scenario in which more complex call types (burst, trills and biphasic) arose from a simpler type (click).

The number of times a new call type is predicted to have appeared across the tree is at least twice for each call type (if S. epitropicalis is included in the biphasic group; Figure 7). Thus, no call type is conserved after divergence. Multiple origins of call types suggest homoplasy of this phenotype.

The expression of a given call type generally does not reflect phylogenetic relationship. For example, the three Silurana species each produce a different call type including the two most closely related species, S. epitropicalis and $S$. new tetraploid 1 . However, other closely related species, for example two within the $X$. borealis clade, produce click type calls and 
three populations of $X$. laevis produce biphasic calls. Variation among closely related species or populations in call type (beyond the exceptions above), suggests that this behavioural characteristic has low phylogenetic signal.

\subsection{Syntopy and call type evolution}

Syntopy could drive call type divergence since species that share a pond would presumably be under pressure to maximize differences between advertisement calls. Although differences in even a single call character can serve to distinguish between species, a more extreme means of differentiation would be changing call type. There are a number of extant species with extensive zones of sympatry (Tinsley et al., 1996); whether different species inhabit the same pond within these zones is not known, but is possible given the frequently noted migration of Xenopus across land during the wet season (Tinsley \& Kobel, 1996; Lobos \& Jaksic, 2005). Some explicit reports of two or three extant species sharing a pond have been published (Picker, 1985; Tinsley et al., 1996; Yager, 1996; Fischer et al., 2000). Support for ancestral syntopy comes from findings that hybridization (with and without genome duplication) has occurred at least eight times in the evolution of new African clawed frog species (Evans, 2008).

Syntopic species that use different call types include $X$. borealis and $X$. victorianus (click and burst types), $X$. laevis South Africa and X. muelleri (biphasic and burst types) and $X$. largeni and $X$. clivii (trill and burst types). One example of three species inhabiting the same pond is $X$. vestitus (trill), X. wittei (trill) and X. laevis South Africa (biphasic); the two species that share a call type (trill) also share a most recent 36 chromosome tetraploid ancestor (see Figure 7).

Of particular interest is the syntopy between X. laevis South Africa and X. gilli (Evans et al., 1998). Here, the $X$. gilli trill and the first portion of the X. laevis South Africa biphasic call are similar in click number and ICI. Interestingly, the iSVUi is equivalent in these species as if the silent period between $X$. gilli advertisement calls was filled in with the second phase of $X$. laevis South Africa advertisement calls, an acoustic feature that would serve to enhance distinction between the species. That extant syntopic species produce different single phase call types — or add a unique acoustic appendage to a similar single phase — is consistent with a role in call type divergence.

\section{Discussion}

\subsection{Comparisons with previous advertisement call type assignments}

We recorded and analyzed advertisement calls from 22 species including 4 diverged populations of African clawed frogs. Of these, two species, $S$. new tetraploid 1 and $X$. new tetraploid, have not yet been described and two, $X$. itombwensis and $X$. lenduensis, represent recent discoveries (Evans et al., 2008, 2011). Advertisement calls from 18 species have been published previously and our data agree with respect to call type for 13 of these (Vigny, 1979; Wetzel \& Kelley, 1983; Fischer et al., 2000); for three species (Vigny, 1979), the reported waveforms are not detailed enough to compare call type.

In some cases the advertisement calls described here differ from those previously reported, possibly because the authors used different criteria for identifying the 'advertisement call'. Xenopus vocal behaviours are specific to social context (Yager, 1992; Tobias et al., 2004). We operationally defined the 'advertisement call' as the one vocalization produced by males in isolation, in same-sex and in different-sex pairings. Based on these criteria, we designated advertisement calls from S. epitropicalis as biphasic (only the second, burst phase was previously reported; Vigny, 1979) and advertisement calls from X. clivii as trills (bursts were previously reported; Vigny, 1979). Similarly, the advertisement call reported by Vigny 
(1979) for X. muelleri is probably an approach call. The X. muelleri advertisement call reported in this study agrees with that reported by Fischer et al. (2000). The present study includes five call characters not previously analyzed - the second dominant frequency, click number, call rate, call duty cycle and intensity modulation. Taken together, this report is the most comprehensive analysis of advertisement calls in African clawed frogs to date.

\subsection{Call types and vocal phylogeny}

In a number of behavioural systems, the trajectory of evolution is from simple to complex. For example, in deer mice, digging long, multi-tunnel burrows evolved from digging small, simple tunnels (Weber \& Hoekstra, 2009). Selective pressures such as predation can also drive the evolution of communication signals from complex to simple, as is believed to have occurred in the waveform of the electric organ discharges of electric fish (Stoddard, 1999). In African clawed frogs, our analyses suggest that the ancestral call was of intermediate complexity (burst type), giving rise both to more complex (biphasic) and simpler (click) call types. The lack of an evolutionary trend towards, or away from, increased complexity suggests there was no selective pressure on this trait.

Homoplasy and a low phylogenetic signal are inconsistent with evolution by genetic drift. Rather, call type divergence appears to have been driven by selective pressures, either natural or sexual. While a low phylogenetic signal could result from rapid evolution, simulation studies show that the phylogenetic signal is constant across a broad range of mutation rates (Revell et al., 2008). In the remainder of this discussion, we consider how adaptation to environmental conditions, morphological and physiological constraints and sexual selection may have contributed to selection for different call types.

\subsection{Adaptation to habitat and call type evolution}

Habitat is known to influence species differences in courtship signalling. For example, in fiddler crabs, species living in the intertidal zone — and, therefore, less visible - have more complex waving displays than species living on higher ground where they are more visible (Sturmbauer et al., 1996). Similarly, the frequency (pitch) of bird songs from different species is adapted to optimize transmission through microhabitat foliages of different densities (Seddon, 2005). African clawed frogs live in slow moving, typically turbid, bodies of water (Tinsley et al., 1996). Although these water bodies are located in a broad range of natural environments, from heavily forested to open savannah, at a variety of altitudes, annual temperature regimes, and $\mathrm{pH}$, there are numerous examples of the same species being found in very different environments and of species with different call types being found in the same ponds. These observations, therefore, suggest that the broader environment is not driving the evolution of call type variation among species.

Habitat could however affect call characters within a call type. For example, X. laevis South Africa call more rapidly (decreased ICI) when reared in warmer temperatures (Yamaguchi et al., 2007). Nonetheless, species from warmer climates, i.e., S. tropicalis, do not have high click rates (this study) and click rate varies dramatically in syntopic species (for example $X$. borealis and $X$. victorianus). Though the possibility that microhabitats influence call characters has not been examined closely, features such as water depth could contribute to species segregation.

\subsection{Morphological and physiological contributions to call type}

Advertisement calls in anurans are produced by the larynx, whose mass can contribute to call pitch. In some anurans, body and larynx size increase allometrically with age and call characters affected by laryngeal morphology can, thus, serve as indicators of fitness (Marquez \& Bosche, 1997). A negative correlation between sound frequency and body size 
has been reported in some frogs (Ryan, 1988) and birds (Wallschlager, 1980). Although body and laryngeal size are also correlated in X. laevis South Africa (Tobias et al., 1991), a correlation between body size and pitch is not found in African clawed frogs. For example, the Silurana species are small and have the lowest frequencies. While the click in African clawed frogs is functionally equivalent to the sound pulses of terrestrial frogs, it is not the product of vibrating vocal structures (Yager, 1992b). An altered mechanism for sound production accompanied the move from terrestrial to aquatic habitats $\sim 170$ mya (Roelants \& Bossuyt, 2005).

In X. laevis South Africa and X. borealis, males produce calls other than the advertisement call and these can differ in spectral and temporal features. For example, the release call in both species has a lower dominant frequency. The six calls of $X$. laevis South Africa males (advertisement, answer, amplectant, chirping, growling and ticking) represent all four call types present in the phylogeny (Tobias et al., 2004). Xenopus borealis produces at least three calls, representing two types (click and trill; Yager, 1992a). Since some species are capable of producing more than one call type some of which differ in dominant frequency, factors beyond physiological and morphological constraints on the vocal organ must contribute to the emergence of a particular advertisement call type in a given species.

\subsection{Sexual selection, species identity and the evolution of call types}

We show here that call type has low phylogenetic signal and infer that it must be under selective pressure. Because advertisement calls convey species identity and individual male qualities, the most likely selective pressure is sexual selection. Species recognition is essential as a pre-mating barrier to hybridization and the consequent decreased viability or fertility of progeny. Examples of vocal signals that convey species identity in other anurans include pulse repetition rate in grey tree frogs (Gerhardt, 1982). Species recognition has also been implicated as a driver of headbob displays in anolis lizards, another complex communication system with low phylogenetic signal (Martins et al., 2004). Advertisement call traits vary between individual males and numerous studies have demonstrated female preference for specific traits (Gerhardt, 1991; Wollerman, 1998; Wilczynski et al., 1999; Kime et al., 2004; Castellano \& Rosso, 2006; Castellano et al., 2009a; Gerhardt \& Brooks, 2009) including biphasic calls (Ryan \& Rand, 1990; Gerhardt et al., 2007). The acoustic features selected for are correlated with male fitness (measured in progeny) in some anuran species (Welch et al., 1998; Forsman \& Hagman, 2006). Intra-sexual selection on vocal behaviours has been less extensively investigated in most species but does appear to play a role in song birds both with respect to call types and acoustic features (Illes et al., 2006).

Whether selection is acting on mate attraction or species recognition can be difficult to assess. Female preference for a specific male trait within her own species does not necessarily translate into choosing a male with this feature in another species. For example, in Drosophila heteroneura, a species with large head width, females prefer larger heads within the species, but don't select larger headed males in heterospecifics (Boake et al., 1997). When female preference for a trait (e.g., tail size in some fish) is very strong, not mating with heterospecific males that evince this trait relies on additional, multiple 'backup signals' in conspecifics (Hankison \& Morris, 2003). Ideally, traits used for conspecific recognition should be invariant while traits used to assess male quality should vary. Call types in African clawed frogs might provide the invariant feature required for reliable species identification. That syntopic species generally use different call types provides support for the notion that call type divergence is selected for as a means to enhance species recognition.

Naturally occurring hybrids between extant syntopic species of African clawed frogs are rarely, if ever, found (Yager, 1996; Evans et al., 1998; Fischer et al., 2000). However, the 
high incidence of ancient hybridization within this group as a whole argues that call type is not an insurmountable barrier to mating. While hybridization between species with the same or different ploidy typically results in infertile males (Kobel \& Du Pasquier, 1986), hybridization between species that may have had distinct call types, nonetheless occurred at least eight times during the evolution of the extant species. The frequency of hybridization may be an underestimate if resultant lineages subsequently went extinct. The origin of polyploid species resulting from hybridization between different ploidy parents involves an intermediate triploid female. When this female mates with a male of one of the parental species (backcrosses), the resultant offspring are fertile and viable and carry both ancestral genomes (reviewed in Evans, 2008). Hybridization, thus, not only creates a new species but also preserves both ancestral genomes. By itself hybridization may not abrogate the need for species recognition so much as offer an alternative productive genetic investment when conditions dictate.

\subsection{Conclusion}

We have shown that males of extant African clawed frogs produce advertisement calls that can be identified by unique acoustic features providing a reliable key to species identity. Advertisement calls can be classified into discrete call types based on temporal features. That call types emerge on distantly related branches, and that phylogenetic relationship and call type are not concordant, strongly suggest that call type evolution reflects selective pressures rather than genetic drift. The most probable selective pressure is sexual selection, including robust signalling of species identity.

\section{Supplementary Material}

Refer to Web version on PubMed Central for supplementary material.

\section{Acknowledgments}

We are grateful to the following people for their help and hospitality while procuring frogs for this study: Richard Tinsley (University of Bristol, Bristol, UK), Andre Solaro and Duri Runger (University of Geneva, Geneva, Switzerland), Mike Picker (University of Cape Town, South Africa) and Caro Hodges (Cape Town, South Africa). Special thanks to Ryan Blum for writing the Signal programs used to measure most call characters.

\section{References}

Blackler AW, Fischberg M. Hybridization of two subspecies of Xenopus laevis. Rev Suisse Zool. $1965 ; 72: 841-857$.

Blomberg SP, Garland T, Ives AR. Testing for phylogenetic signal in comparative data: behavioral traits are more labile. Evolution. 2003; 57:717-745. [PubMed: 12778543]

Boake CRB, DeAngelis MP, Andreadis DK. Is sexual selection and species recognition a continuum? Mating behavior of the stalk-eyed fly Drosophila heteroneura. Proc Natl Acad Sci USA. 1997; 94:12442-12445. [PubMed: 9356468]

Borgia G, Coleman SW. Co-option of male courtship signals from aggressive display in bowerbirds. Proc Roy Soc Lond B: Biol. 2000; 267:1735-1740.

Bradbury, JW.; Vehrencamp, SL. Principles of animal communication. Sinauer; Sunderland, MA: 1998.

Cannatella DC, Hillis DM, Chippindale PT, Weight L, Rand SA, Ryan MJ. Phylogeny of frogs of the Physalaemus pustulosus species group, with an examination of data incongruence. Syst Biol. 1998; 47:311-335. [PubMed: 12064230]

Castellano S, Marconi V, Zanollo V, Berto G. Alternative mating tactics in the Italian treefrog, Hyla intermedia. Behav Ecol Sociobiol. 2009a; 63:1109-1118.

Castellano S, Rosso A. Variation in call temporal properties and female preferences in Hyla intermedia. Behaviour. 2006; 143:405-424. 
Castellano S, Tontini L, Giacoma C, Lattes A, Balletto E. The evolution of release and advertisement calls in green toads (Bufo viridis complex). Biol J Linn Soc. 2002; 77:379-391.

Castellano S, Zanollo V, Marconi V, Berto G. The mechanisms of sexual selection in a lek-breeding anuran, Hyla intermedia. Anim Behav. 2009b; 77:213-224.

Cocroft RB, Ryan MJ. Patterns of advertisement call evolution in toads and chorus frogs. Anim Behav. 1995; 49:283-303.

Dubois AL, Nowicki S, Searcy WA. Swamp sparrows modulate vocal performance in an aggressive context. Biol Lett. 2009; 5:163-165. [PubMed: 19087921]

Evans BJ. Ancestry influences the fate of duplicated genes millions of years after polyploidization of clawed frogs (Xenopus). Genetics. 2007; 176:1119-1130. [PubMed: 17435227]

Evans BJ. Genome evolution and speciation genetics of clawed frogs (Xenopus and Silurana). Front Biosci. 2008; 13:4687-4706. [PubMed: 18508539]

Evans BJ, Carter TF, Tobias ML, Kelley DB, Hanner R, Tinsley RC. A new species of clawed frog (genus Xenopus) from the Itombwe Massif, Democratic Republic of the Congo: implications for DNA barcodes and biodiversity conservation. Zootaxa. 2008; 1780:55-68.

Evans BJ, Greenbaum E, Kusumba C, Carter TF, Tobias ML, Mendel D, Kelley D. Description of a new octoploid frog species (Anura: Pipidae: Xenopus) from the Democratic Republic of the Congo, with a discussion of the biogeography of African clawed frogs in the Albertine Rift. J Zool. 2011; 283:276-290.

Evans BJ, Kelley D, Tinsley RC, Melnick D, Cannatella DC. A mitochondrial DNA phylogeny of African clawed frogs: phylogeography and implications for polyploid evolution. Mol Phylogen Evol. 2004; 33:197-213.

Evans BJ, Morales JC, Picker MD, Melnick D, Kelley D. Absence of extensive introgression between Xenopus gilli and Xenopus laevis laevis (Anura: Pipidae) in Southwestern Cape Province, South Africa. Copeia. 1998; 1998:504-509.

Felsenstein J. Phylogenies and the comparative method. Am Nat. 1985; 125:1-15.

Fischer WJ, Koch WA, Elepfandt A. Sympatry and hybridization between the clawed frogs Xenopus laevis laevis and Xenopus muelleri (Pipidae). J Zool. 2000; 252:99-107.

Forsman A, Hagman M. Calling is an honest indicator of paternal genetic quality in male poison frogs. Evolution. 2006; 60(10):2148-2157. [PubMed: 17133871]

Gentner TQ, Hulse SH. Female European starling preference and choice for variation in conspecific male song. Anim Behav. 2000; 59:443-458. [PubMed: 10675267]

Gerhardt HC. Sound pattern recognition in some North American treefrogs (Anura: Hylidae): implications for mate choice. Am Zool. 1982; 22:581-595.

Gerhardt HC. Female mate choice in treefrogs: static and dynamic acoustic criteria. Anim Behav. 1991; 42:615-635.

Gerhardt HC, Brooks R. Experimental analysis of multivariate female choice in Gray Treefrogs (Hyla versicolor): evidence for directional and stabilizing selection. Evolution. 2009; 63:2504-2512. [PubMed: 19500145]

Gerhardt, HC.; Huber, F. Acoustic communication in insects and anurans. University of Chicago Press; Chicago: 2002.

Gerhardt HC, Humfeld SC, Marshall VT. Temporal order and the evolution of complex acoustic signals. Proc Roy Soc Lond B: Biol. 2007; 274:1789-1794.

Hankison SJ, Morris MR. Avoiding a compromise between sexual selection and species recognition: female swordtail fish assess multiple species-specific cues. Behav Ecol. 2003; 4:282-287.

Holloway AK, Cannatella DC, Gerhardt HC, Hillis DM. Polyploids with different origins and ancestors form a single sexual polyploid species. Am Nat. 2006; 167:88-101.

Illes AE, Hall ML, Vehrencamp SL. Vocal performance influences male receiver response in the banded wren. Proc Roy Soc Lond B: Biol. 2006; 273:1907-1912.

Keller MJ, Gerhardt HC. Polyploidy alters advertisement call structure in gray treefrogs. Proc Roy Soc Lond B: Biol. 2001; 268:341-345.

Kelley, DB.; Tobias, ML. The vocal repertoire of Xenopus laevis. In: Konishi, M.; Hauser, M., editors. The design of animal communication. MIT Press; Cambridge, MA: 1999. p. 9-35. 
Kime NM, Burmeister SS, Ryan MJ. Female preferences for socially variable call characters in the cricket frog, Acris crepitans. Anim Behav. 2004; 68:1391-1399.

Kobel HR, Du Pasquier L. Genetics of polyploid Xenopus. Trends Genet. 1986; 12:310-315.

Kobel, HR.; Loumont, C.; Tinsley, RC. The extant species. In: Tinsley, R.; Kobel, H., editors. The biology of Xenopus. Clarendon Press; Oxford: 1996. p. 9-31.

Kusmierski R, Borgia G, Crozier RH, Chan BHY. Molecular information on bowerbird phylogeny and the evolution of exaggerated male characteristics. J Evol Biol. 1993; 6:737-752.

Lobos G, Jaksic FM. The ongoing invasion of African clawed frogs (Xenopus laevis) in Chile: causes of concern. Biodiv Conserv. 2005; 14:429-439.

Lovejoy NR, Lester K, Crampton WGR, Marques FPL, Albert JS. Phylogeny, biogeopraphy, and electric signal evolution of Neotropical knifefishes of the genus Gymnotus (Osteichthyes: Gymnotidae). Mol Phylogen Evol. 2010; 54:278-290.

Marquez R, Bosche J. Female preference in complex acoustical environments in the midwife toads Alytes obstetricans and Alytes cisternasii. Behav Ecol. 1997; 8:588-594.

Martins EP, Labra A, Halloy M, Thompson JT. Large-scale patterns of signal evolution: an interspecific study of Liolaemus lizard headbob displays. Anim Behav. 2004; 68:453-463.

Measey GJ, Channing A. Phylogeography of the genus Xenopus in southern Africa. AmphibiaReptilia. 2003; 24:321-330.

Morris MR, Tudor MS, Dubois NS. Sexually selected signal attracted females before deterring aggression in rival males. Anim Behav. 2007; 74:1189-1197.

Nasipak BT, Kelley DB. The genome of the diploid anuran Xenopus tropicalis contains a novel array of sarcoplasmic myosin heavy chain genes expressed in larval muscle and larynx. Dev Genet Evol. 2008; 218:389-397.

Ord TJ, Blumstein DT, Evans CS. Intrasexual selection predicts the evolution of signal complexity in lizards. Proc Roy Soc Lond B: Biol. 2001; 268:737-744.

Pagel M, Meade A, Barker D. Bayesian estimation of ancestral character states on phylogenies. Syst Biol. 2004; 53:673-684. [PubMed: 15545248]

Pfennig KS, Rapa K, McNatt R. Evolution of male mating behavior: male spadefoot toads preferentially associate with conspecific males. Behav Ecol Sociobiol. 2000; 48:69-74.

Picker MD. Hormonal induction of the aquatic phonotactic response of Xenopus. Behaviour. 1983; 84:74-90.

Picker MD. Hybridization and habitat selection in Xenopus gilli and Xenopus laevis in the southwestern Cape Province. Copeia. 1985:574-580.

Price JJ, Friedman NR, Omland KE. Song and plumage evolution in the new world orioles (Icterus) show similar lability and convergence in patterns. Evolution. 2007; 61:850-863. [PubMed: 17439617]

Ptacek MB, Gerhardt HC, Sage RD. Speciation by polyploidy in treefrogs: multiple origins of the tetraploid, Hyla versicolor. Evolution. 1994; 48:898-908.

Revell LJ, Harmon LJ, Collar DC. Phylogenetic signal, evolutionary process, and rate. Syst Biol. 2008; 57:591-601. [PubMed: 18709597]

Roelants K, Bossuyt F. Archaeobatrachian paraphyly and pangaean diversification of crown-group frogs. Syst Biol. 2005; 54:111-126. [PubMed: 15805014]

Ryan, M. Constraints and patters in the evolution of anuran acoustic communication. In: Fritzsch, B.; Ryan, M.; Wilczynski, W.; Hetherington, T.; Walkowiak, W., editors. The evolution of the amphibian auditory system. Wiley; New York, NY: 1988. p. 637-677.

Ryan M, Rand SA. The sensory basis of sexual selection for complex calls in the Tungara frog, Physalaemus pustulosus (Sexual selection for sensory exploitation). Evolution. 1990; 44:305-314.

Ryan M, Tuttle AS, Rand SA. Bat predation and sexual advertisement in a neotropical anuran. Am Nat. 1982; 119:136-139.

Ryan MJ. Female responses to ancestral advertisement calls in tungara frogs. Science. 1995; 269:390392. [PubMed: 17841263]

Ryan MJ, Brenowitz EA. The role of body size, phylogeny, and ambient noise in the evolution of bird song. Am Nat. 1985; 126:87-100. 
Sanvito S, Galimbreti F, Miller EH. Vocal signalling of male southern elephant seals is honest but imprecise. Anim Behav. 2007; 73:287-299.

Seddon N. Ecological adaptation and species recognition drives vocal evolution in neotropical suboscine birds. Evolution. 2005; 59:200-215. [PubMed: 15792239]

Stoddard PK. Predation enhances complexity in the evolution of electric fish signals. Nature. 1999; 400:254-256. [PubMed: 10421365]

Sturmbauer C, Levinton JS, Christy J. Molecular phylogeny analysis of fiddler crabs: test of the hypothesis of increasing behavioral complexity in evolution. Proc Natl Acad Sci USA. 1996; 93:10855-10857. [PubMed: 11607711]

Thierry B, Aureli F, Nunn CL, Petit O, Abegg C, de Waal FBM. A comparative study of conflict resolution in macaques: insights into the nature of trait covariation. Anim Behav. 2008; 75:847860.

Tinsley, RC.; Kobel, HR. The biology of Xenopus. Clarendon Press; Oxford: 1996.

Tinsley, RC.; Loumont, C.; Kobel, HR. Geographical distribution and ecology. In: Tinsley, RC.; Kobel, HR., editors. The biology of Xenopus. The Zoological Society of London; Oxford: 1996. p. 35-56.

Tobias ML, Barnard C, O'Hagan R, Horng SH, Rand M, Kelley DB. Vocal communication between male Xenopus laevis. Anim Behav. 2004; 67:353-365. [PubMed: 23457414]

Tobias ML, Corke A, Korsh J, Yin D, Kelley DB. Vocal competition in male Xenopus laevis frogs. Behav Ecol Sociobiol. 2010; 64:1791-1803. [PubMed: 21442049]

Tobias ML, Marin ML, Kelley DB. Development of functional sex differences in the larynx of Xenopus laevis. Dev Biol. 1991; 147:251-259. [PubMed: 1879611]

Vigny C. Mating calls of 12 species and sub-species of the genus Xenopus (Amphibia, Anura). J Zool. 1979; 188:103-122.

Wallschlager D. Correlation of song frequency and body weight in Passerine birds. Experientia. 1980; $36: 412-412$.

Weber JN, Hoekstra HE. The evolution of burrowing behaviour in deer mice (genus Peromyscus). Anim Behav. 2009; 77:603-609.

Welch AM, Semlitsch RD, Gerhardt HC. Call duration as a reliable indicator of genetic quality in the gray tree frog. Science. 1998; 280:1928-1930. [PubMed: 9632389]

Wetzel DM, Kelley DB. Androgen and gonadotropin effects on male mate calls in South-African clawed frogs, Xenopus laevis. Horm Behav. 1983; 17:388-404. [PubMed: 6662518]

Wilczynski W, Rand SA, Ryan MJ. Female preferences for temporal order of call components in the tungara frog: a Bayesian analysis. Anim Behav. 1999; 58:841-851. [PubMed: 10512658]

Wollerman L. Stabilizing and directional prefereces of female Hyla ebraccata for calls differing in static properties. Anim Behav. 1998; 55:1619-1630. [PubMed: 9642005]

Yager DD. Underwater acoustic communication in the African pipid frog Xenopus borealis. Bioacoustics. 1992a; 4:1-24.

Yager DD. A Unique Sound production mechanism in the Pipid anuran Xenopus borealis. Zool J Linn Soc. 1992b; 104:351-375.

Yamaguchi A, Gooler D, Herrold A, Patel S, Pong WW. Temperature-dependent regulation of vocal pattern generator. J Neurophysiol. 2007; 100:3134-3143. [PubMed: 18829853] 

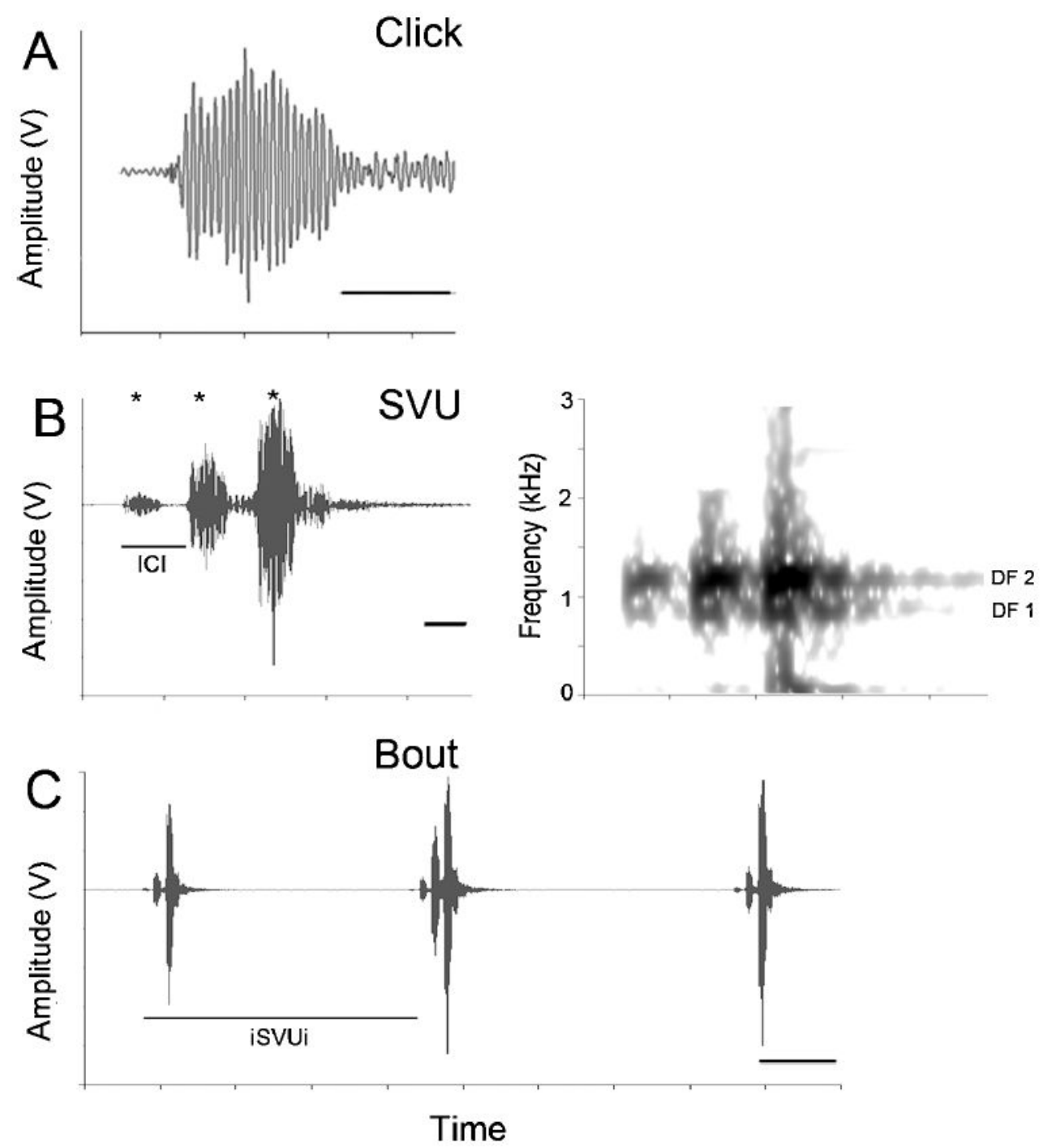

Figure 1.

The units of advertisement calling in African clawed frogs. This example is taken from $X$. clivii. (A) Click: the smallest unit of sound. Calibration bar $=10 \mathrm{~ms}$. (B) SVU: a repeating pattern of clicks, equivalent to one advertisement call. Here, one SVU is composed of 3 clicks, increasing in amplitude throughout the SVU. The click shown in A is the middle click in B. An asterisk (*) indicates each click and was used to determine click number. Line labeled ICI indicates the time interval from the beginning of one click to the beginning of the next. DF1 and DF2 are indicated on the spectrogram (B, right). Amplitude vs. time (ms) is shown on the left and frequency vs time is shown on the right. Calibration bar $=10 \mathrm{~ms}$. (C) Bout: a bout contains a number of SVUs occurring at regular intervals. Here, a bout contains 3 SVUs; the middle SVU is that shown in B. Line labeled iSVUi indicates the time interval from the beginning of one SVU to the beginning of the next. Amplitude vs time (s). Calibration bar $=100 \mathrm{~ms}$. 


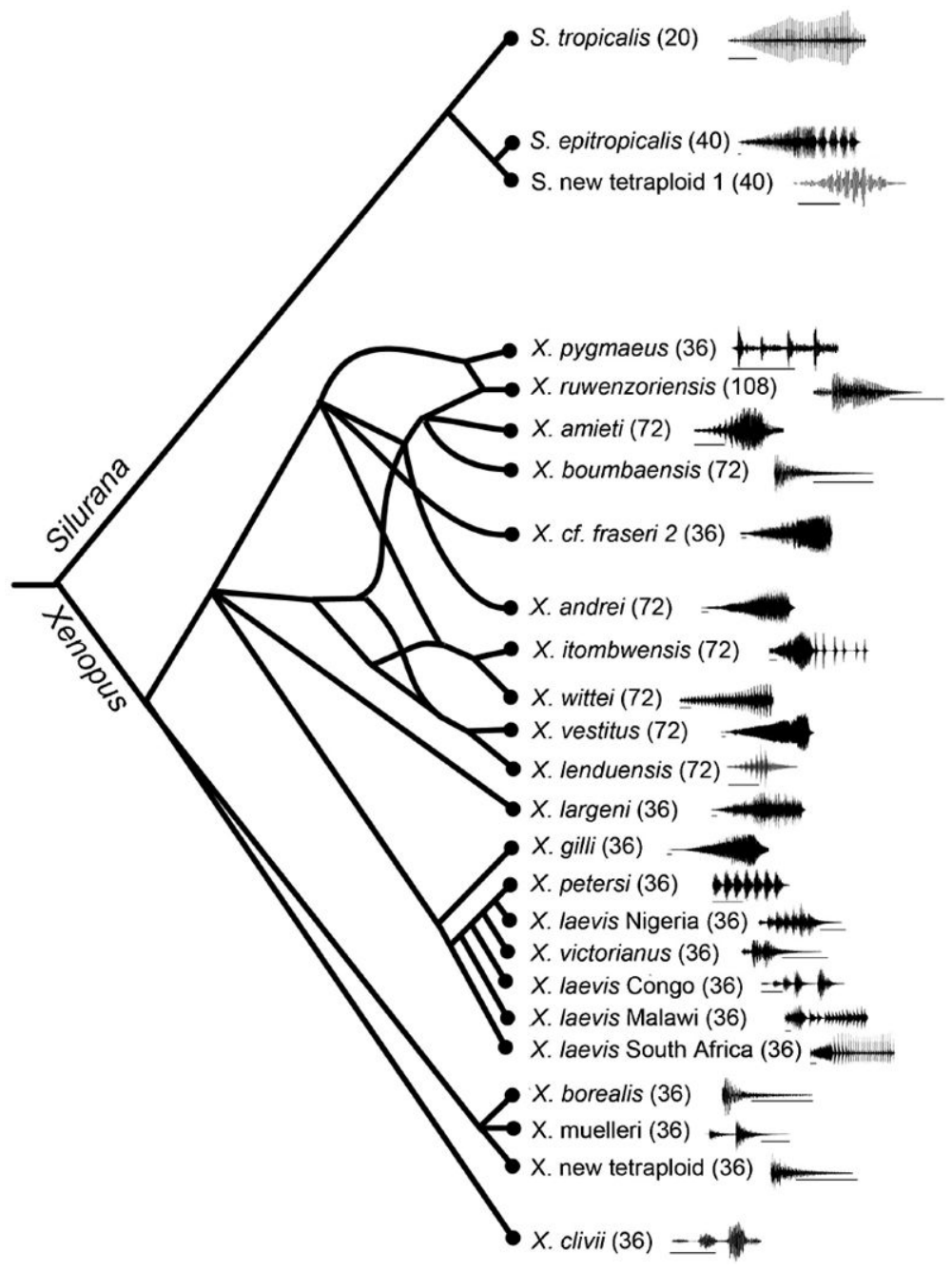

Figure 2.

Advertisement calls and molecular phylogeny of African clawed frogs. Only species recorded from in this study are shown. A waveform of one SVU from each species is indicated to the right of the species name (or location, for the four populations of $X$. laevis). Numbers in parentheses refer to chromosome number (for Silurana $20=$ diploid, $40=$ tetraploid; for Xenopus $36=$ tetraploid, $72=$ octoploid and $108=$ dodecaploid). Calibration bar $=50 \mathrm{~ms}$. 
Click

A

X. borealis
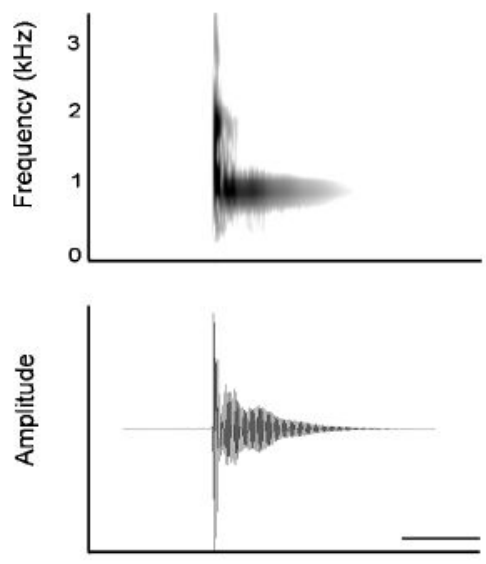

B

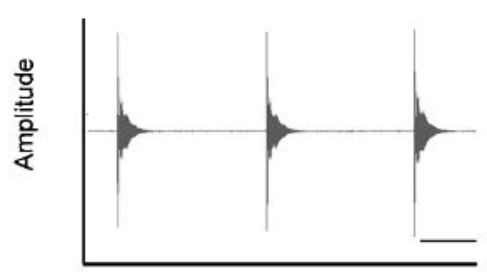

Burst

S. new tetraploid 1
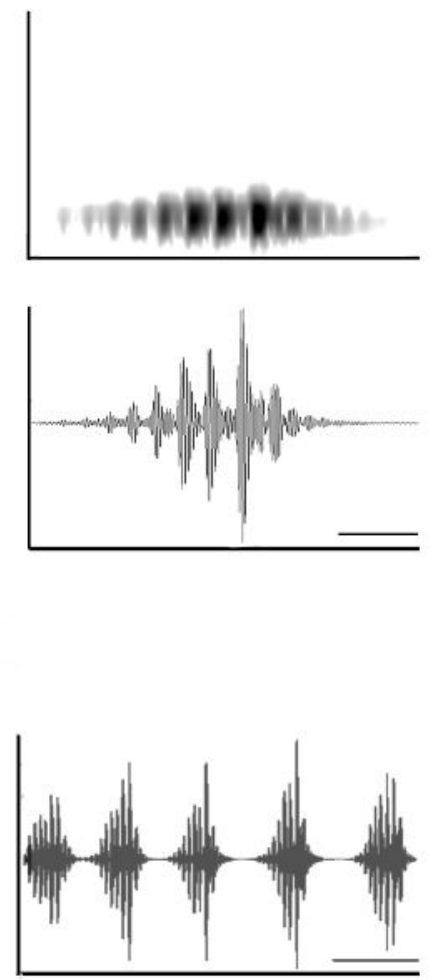

Trill

$X$. vestitus
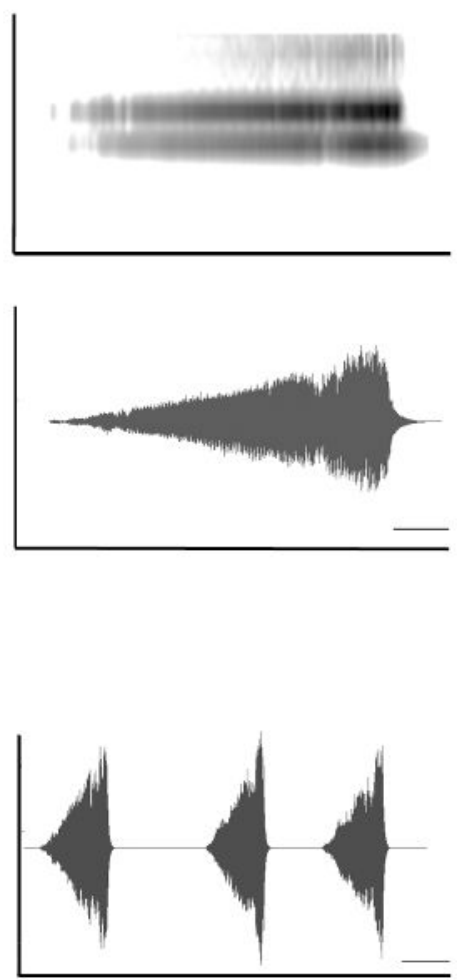

Figure 3.

Advertisement calls are categorized into three call types - click (left), burst (middle) and trill (right). (A) Spectrogram (top) and waveform (bottom) are shown for one SVU of each call type. Calibration bars: click and burst $=50 \mathrm{~ms}$, trill $=200 \mathrm{~ms}$. (B) A bout of calling from which the SVU in A was taken. Calibration bars: click $=200 \mathrm{~ms}$, burst $=250 \mathrm{~ms}$, trill = $1 \mathrm{~s}$. 

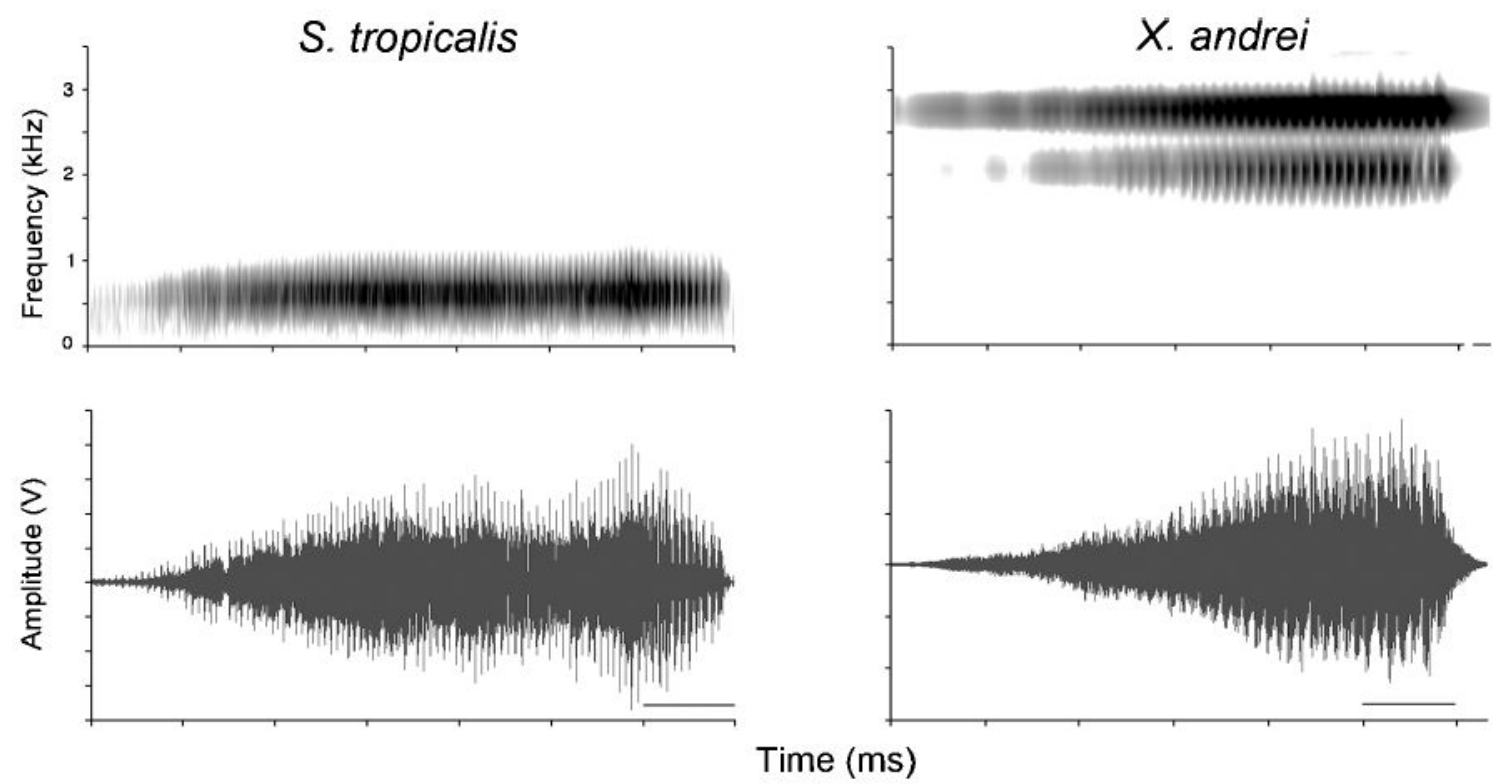

Figure 4.

Silurana and Xenopus species are distinguished by spectral profile. Silurana species (left; one SVU from $S$. tropicalis) have one low frequency dominant peak (approx. $500 \mathrm{~Hz}$ ), while Xenopus species (right; one SVU from $X$. andrei) have two higher frequency dominant peaks (approx. 2.0 and approx. $2.7 \mathrm{kHz}$ ). Top traces indicate spectrograms (frequency vs. time); bottom traces indicate waveforms (amplitude vs. time). Calibration bars: $500 \mathrm{~ms}$ (left), $100 \mathrm{~ms}$ (right). 


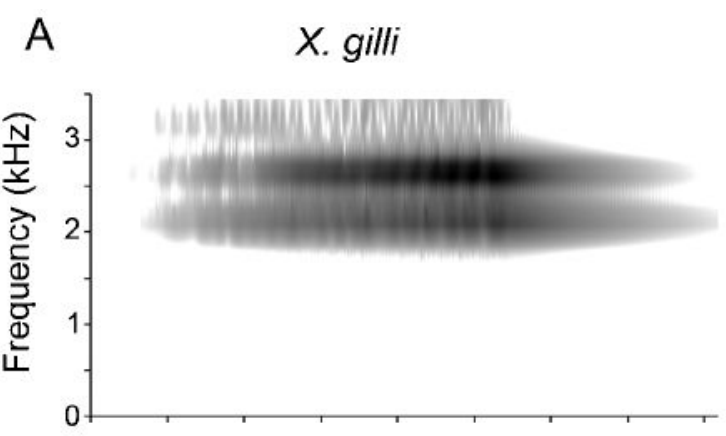

B X. laevis
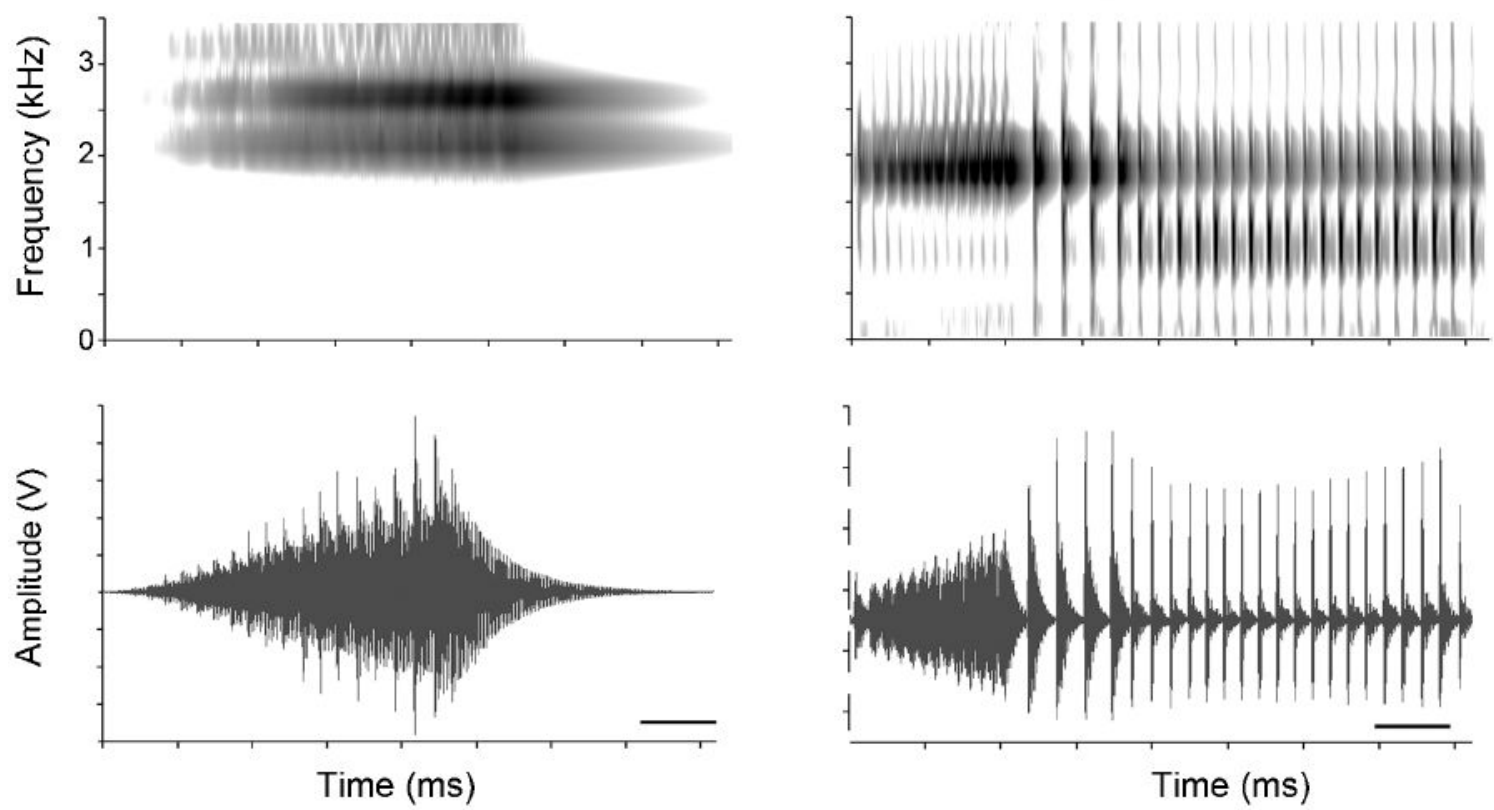

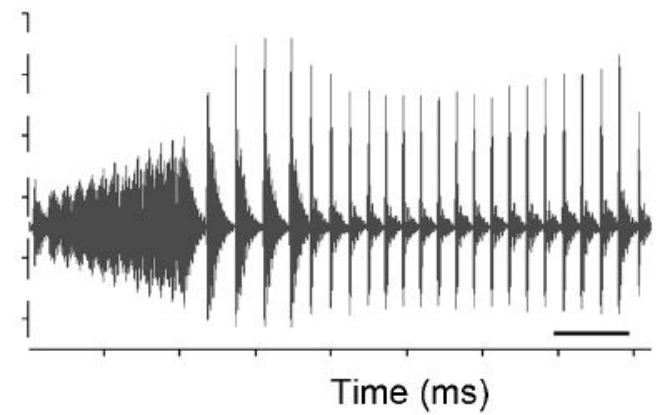

Figure 5.

Single phase calls have one and biphasic calls have two temporal patterns. A representative single phase call from $X$. gilli (left) and a representative biphasic call from $X$. laevis South Africa (right). Top traces are spectrograms (frequency vs. time); bottom traces are waveforms (amplitude vs. time). Calibration bars: $50 \mathrm{~ms}$ (left), $100 \mathrm{~ms}$ (right). 
A

A $\quad X$ itombwensis
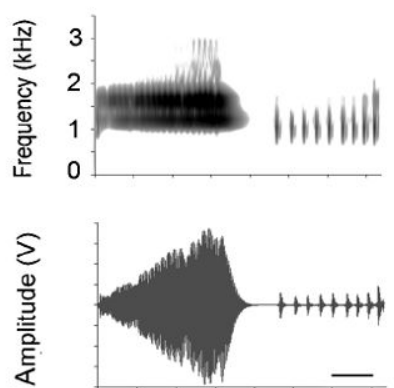

$\mathrm{B}$

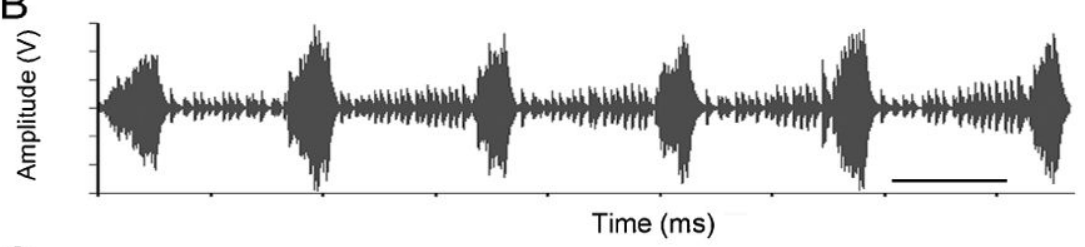

C

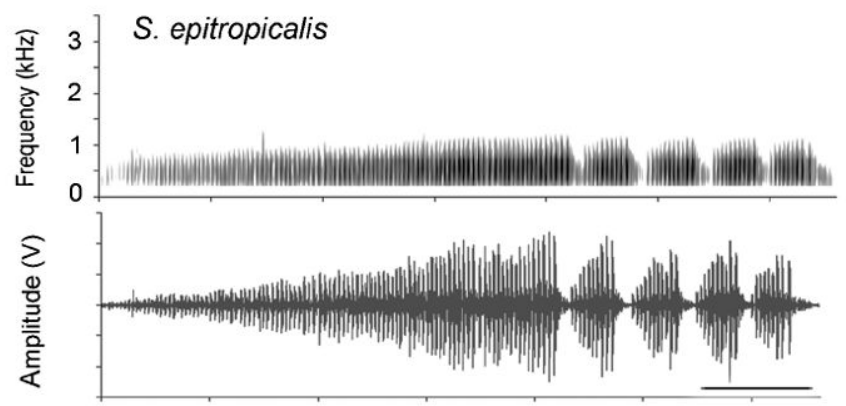

Figure 6.

The temporal pattern of biphasic calls varies by species. (A) Representative SVUs from three biphasic callers. (Left) X. itombwensis calls consist of a rapid trill followed by a slower burst (unlike most bursts, there is no intensity modulation for this slow burst). (Middle) $X$. laevis Congo consists of a burst (4 clicks) followed by a single click after a longer pause. (Right) X. laevis Malawi consists of a rapid trill followed by a slower trill. Calibration bar = $100 \mathrm{~ms}$. (B) Portion of a bout from X. laevis Malawi illustrating the characteristic regular pattern of SVUs, here alternating fast and slow trills. Calibration bar $=500 \mathrm{~ms}$. (C) SVU of S. epitropicalis. The most common pattern of calling for this species is that shown here, a long rapid trill followed by a bout of bursts. Calibration bar $=500 \mathrm{~ms}$. (D) A bout of calling from S. epitropicalis illustrating the irregular pattern of short to long trills. Calibration bar = $2.5 \mathrm{~s}$. 


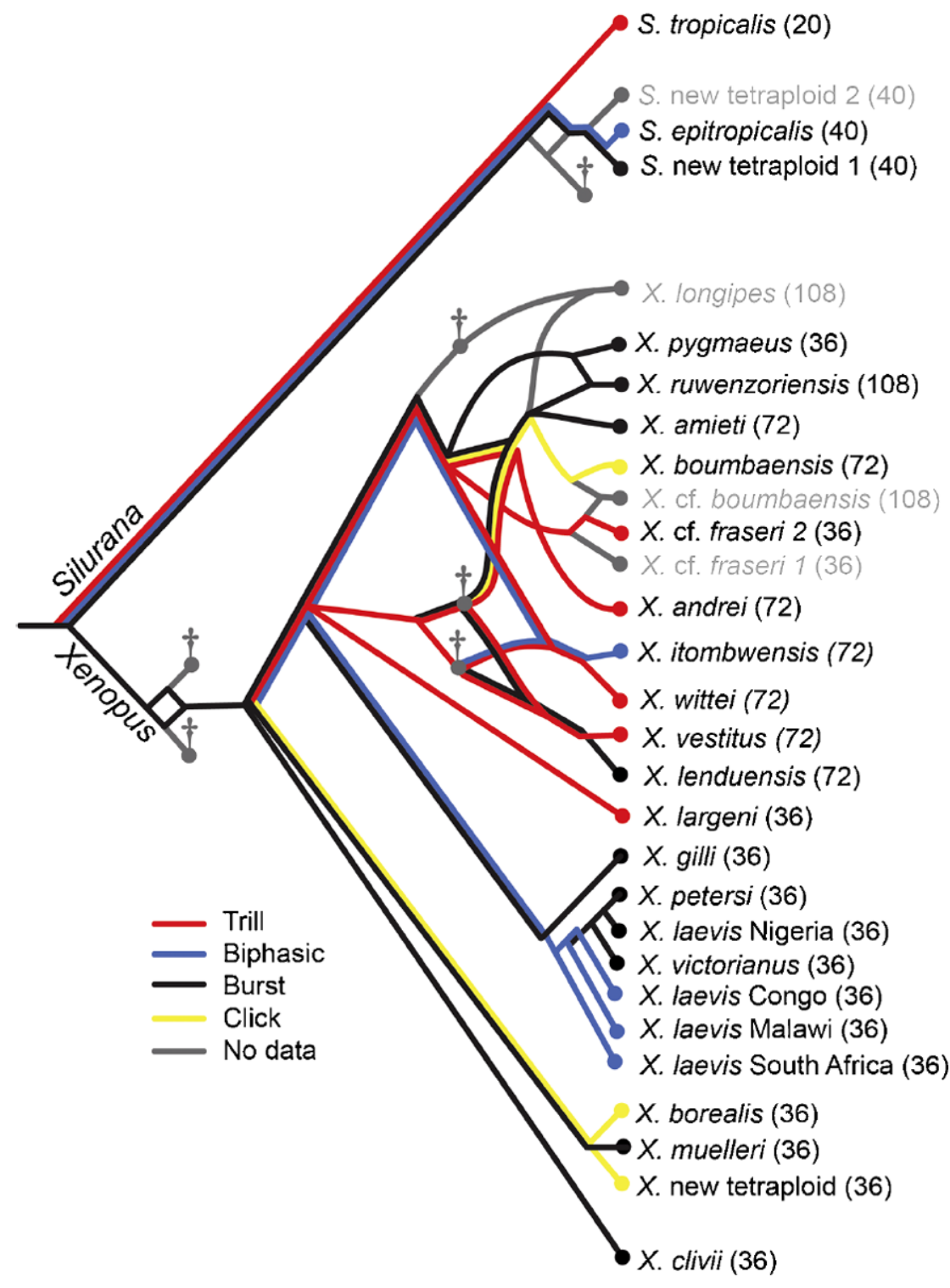

Figure 7.

Call types mapped onto a molecular phylogenetic tree for African clawed frogs. All known species, including museum samples and one extant species not recorded (gray lines) are shown. Predicted ancestral species with unknown same ploidy descendants are indicated by crosses. Call types are colour-coded as indicated. Each call type has evolved at least twice. Maximum parsimony analyses suggest that the ancestral call type was a burst, a call of intermediate complexity. This figure is published in colour in the online edition of this journal, which can be accessed via http://www.brill.nl/beh 


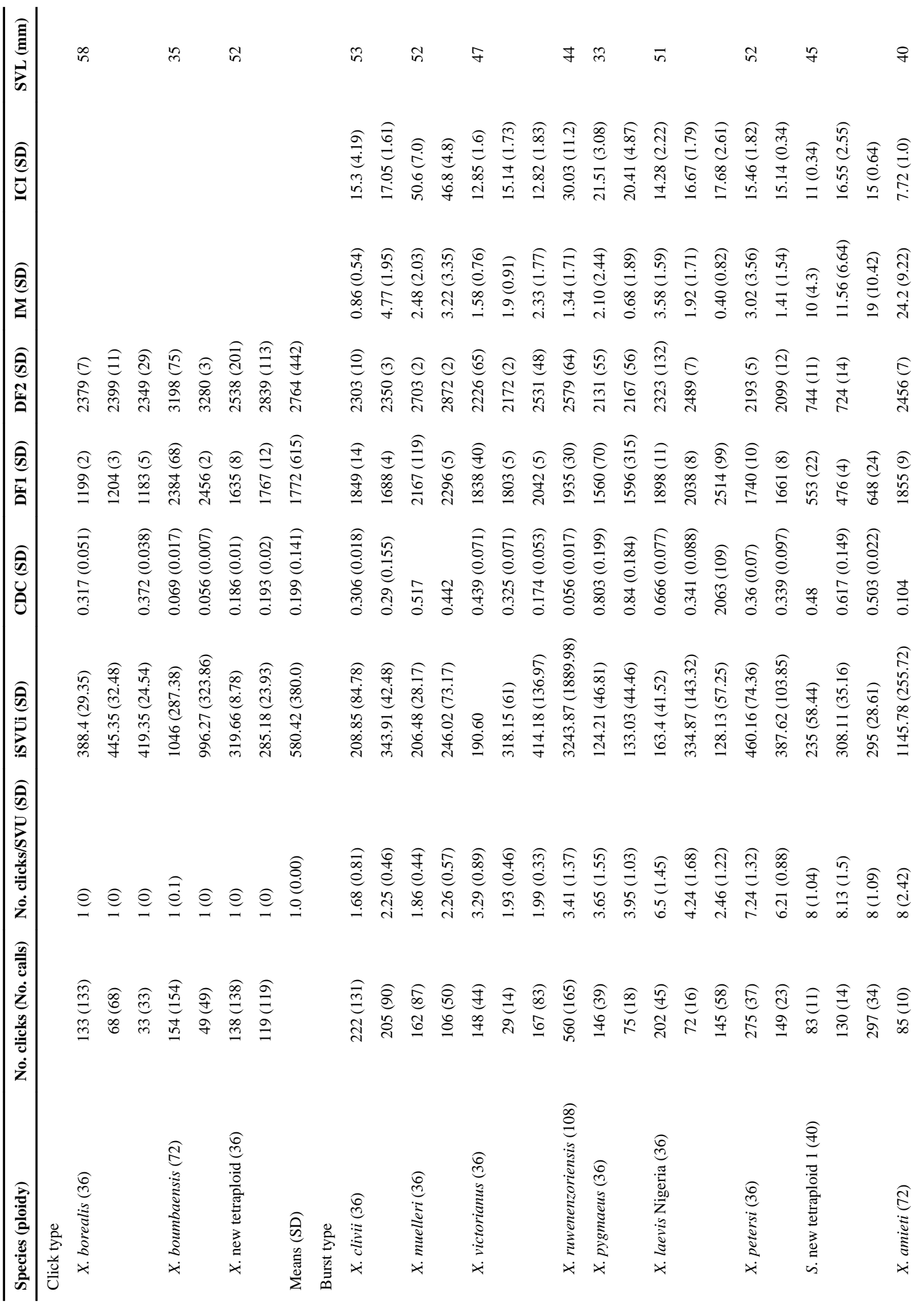




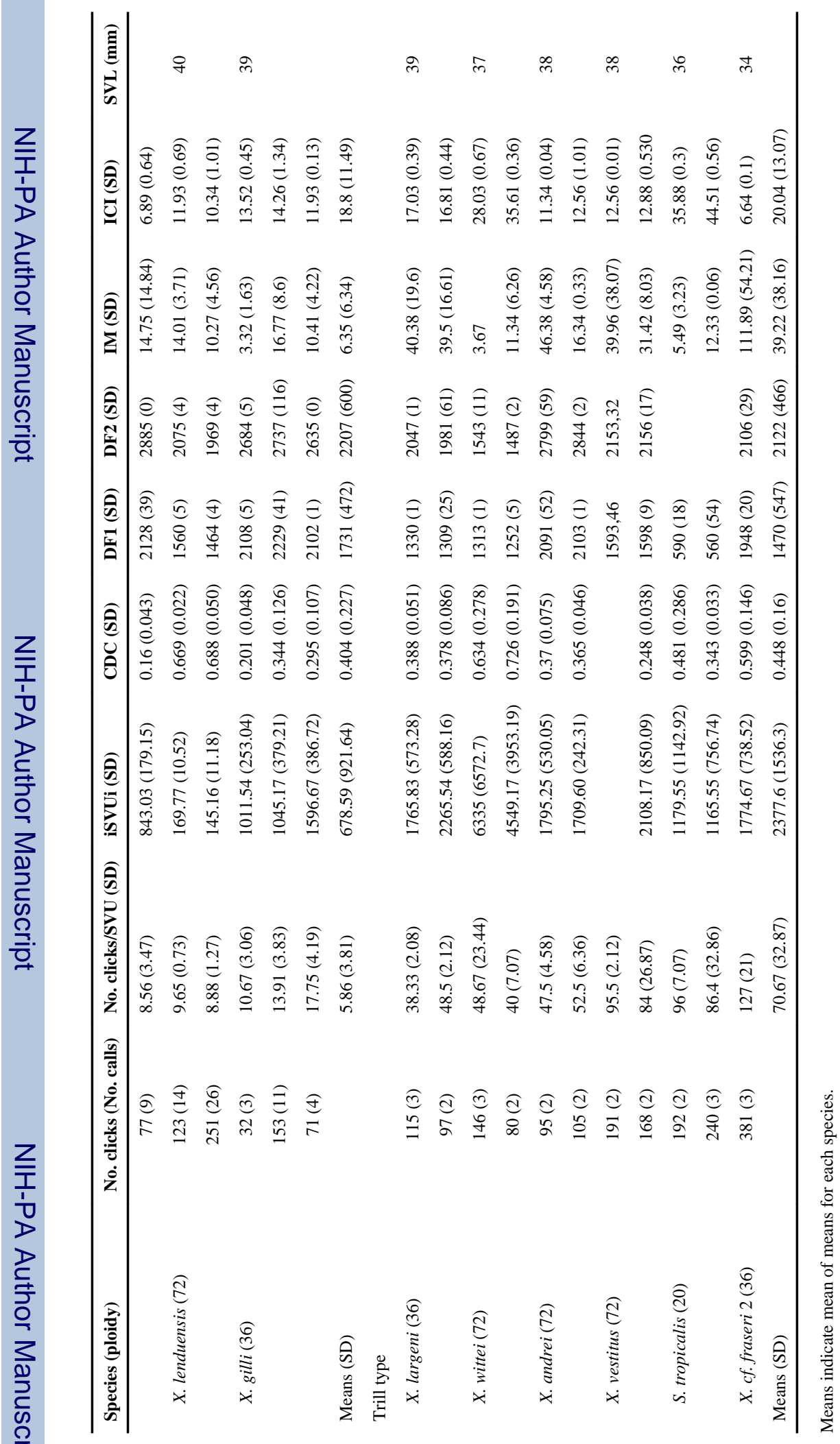




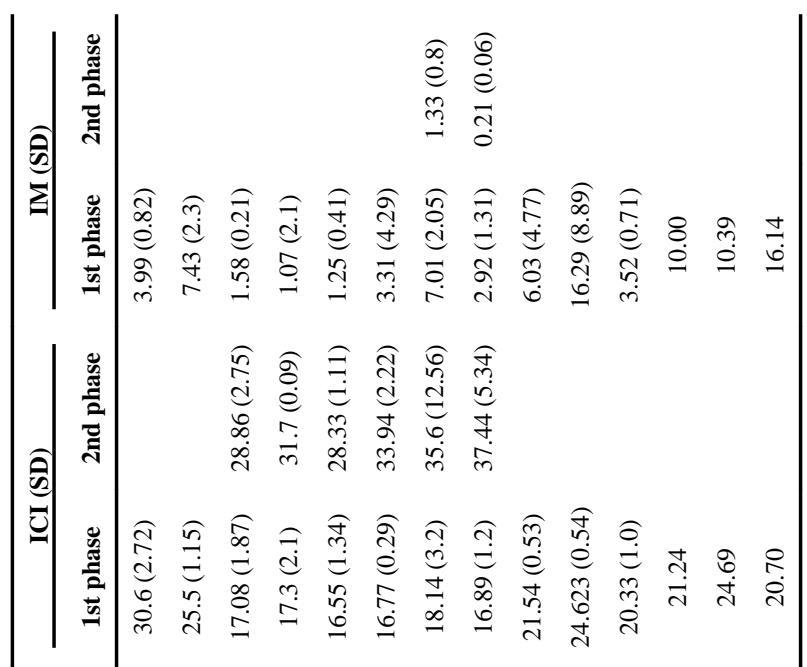

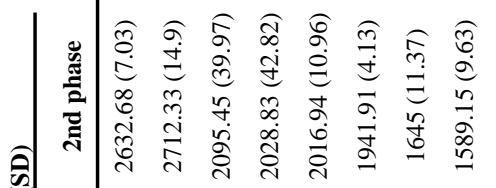

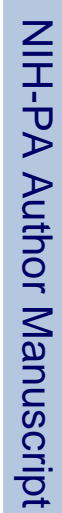

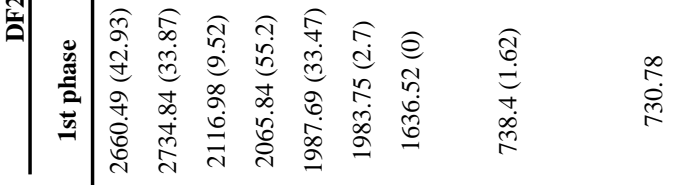

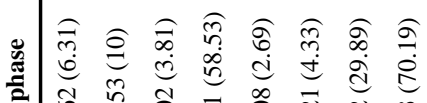

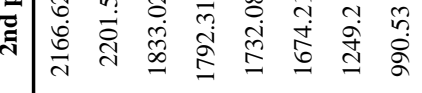

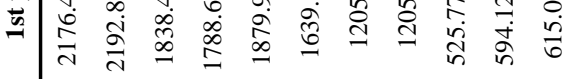

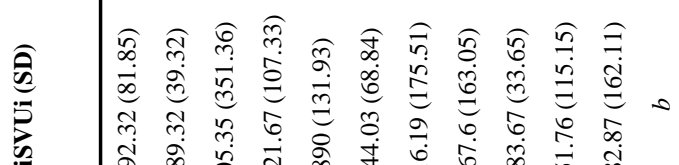

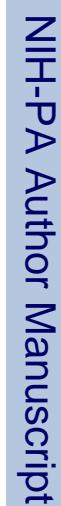

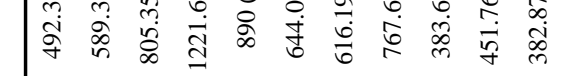

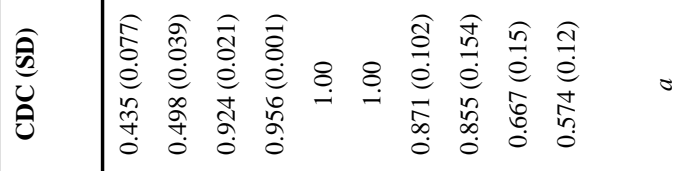

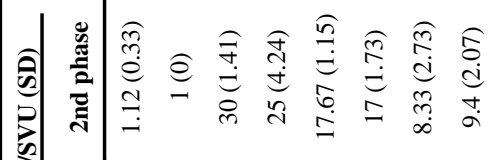

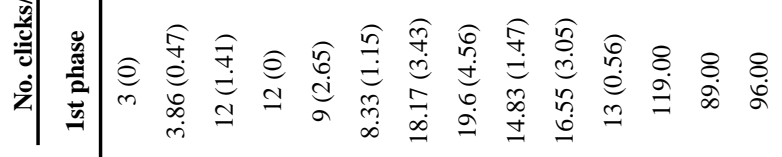

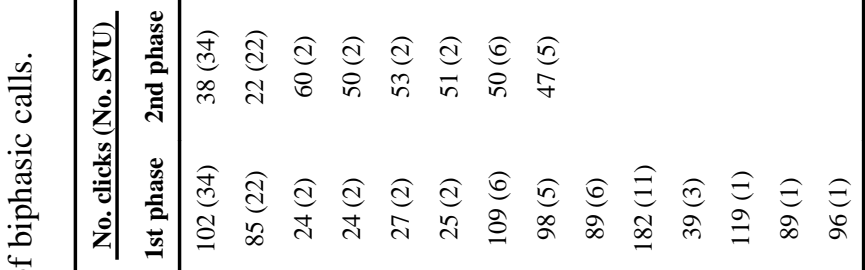

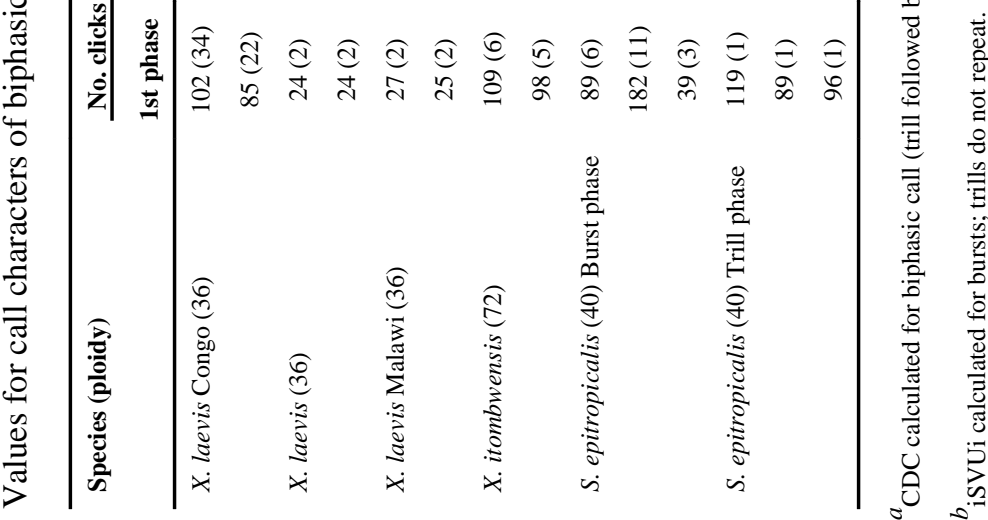

